\title{
FERTILIZANTE DE LIBERAÇÃO LENTA NO CRESCIMENTO E QUALIDADE DE MUDAS DE CANAFÍSTULA (Peltophorum dubium)
}

\author{
Tiago Reis Dutra $^{1 *}$, Marília Dutra Massad ${ }^{1}$, Mateus Felipe Quintino Sarmento ${ }^{2}$ \\ ${ }^{1}$ Instituto Federal do Norte de Minas Gerais, Salinas, Minas Gerais, Brasil - tiagoreisdutra@gmail.com*; mariliamassad@yahoo.com.br \\ ${ }^{2}$ Universidade Federal dos Vales do Jequitinhonha e Mucuri, Diamantina, Minas Gerais, Brasil - mateusengflorestal@ hotmail.com
}

Recebido para publicação: 28/12/2015 - Aceito para publicação: 18/11/2016

\begin{abstract}
Resumo
O presente trabalho objetivou avaliar o crescimento e a qualidade de mudas de canafístula (Peltophorum dubium (Spreng.) Taub.) em resposta à aplicação de diferentes doses e formulações do fertilizante de liberação lenta (FLL) Osmocote ${ }^{\circledR}$. Adotou-se o delineamento em blocos casualizados, com três repetições, no esquema fatorial 2 × 5, formado por duas formulações de Osmocote ${ }^{\circledR}(15-09-12$ com liberação de 5 à 6 meses; e 19-06-10 com liberação de 3 à 4 meses) e cinco dosagens dos mesmos $(0 ; 2,5 ; 5,0 ; 7,5$ e 10,0 g dm ${ }^{3}$ ). Foram avaliados: altura, diâmetro do coleto, massa seca parte aérea, raiz e total, além das relações altura/diâmetro do coleto, altura/massa seca parte aérea, massa seca parte aérea/massa seca raiz e o índice de qualidade de Dickson. As mudas de canafístula responderam ao uso do FLL Osmocote ${ }^{\circledR}$, apresentando melhores resultados de crescimento e padrão de qualidade sob doses entre 5,4 a $8,2 \mathrm{~g} \mathrm{dm}^{-3}$. A formulação 1906-10 foi capaz de proporcionar a produção de mudas de Peltophorum dubium com bom crescimento. Palavras-chave: Espécie florestal nativa; nutrição de plantas; produção de mudas; Osmocote ${ }^{\circledR}$.
\end{abstract}

\begin{abstract}
Slow release fertilizer on the growth and seedlings quality of canafistula (Peltophorum dubium (Spreng.) Taub.). This study aimed to evaluate the growth and quality of canafístula seedlings (peltophorum dubium (Spreng.) Taub.) In response to different doses and formulations of slow release fertilizer (FLL) Osmocote ${ }^{\circledR}$. The design was adopted in a randomized block design with three replications, in a factorial $2 \times 5$, consisting of two formulations of Osmocote ${ }^{\circledR}$ (15-09-12 with release 5 to 6 months, and with the release of 19-06-10 3 to 4 months old) and five of the same dosages $\left(0,2.5,5.0,7.5\right.$ and $\left.10.0 \mathrm{~g} \mathrm{dm}^{-3}\right)$. Were evaluated: height, stem diameter, dry matter shoot, root and all, in addition to the height / stem diameter, height / shoot dry weight, dry weight shoot / dry root mass and Dickson quality index. The canafístula seedlings responded to the use of FLL Osmocote ${ }^{\circledR}$, with better growth and quality standard in doses ranging from 5.4 to $8.2 \mathrm{~g} \mathrm{dm}^{-3}$. The formulation 19-06-10 was able to provide for the production of Peltophorum dubium seedlings with good growth.

Keywords: Native forest species; plant nutrition; production of seedlings; Osmocote ${ }^{\circledR}$.
\end{abstract}

\section{INTRODUÇÃO}

A crescente consciência ambiental por parte da população além das cobranças de órgãos competentes sobre a aplicação da legislação florestal vigente têm fomentado uma crescente utilização de espécies florestais nativas em empreendimentos conservacionistas. Da mesma forma, o plantio dessas espécies para fins comerciais de seus produtos madeireiros e não madeireiros estão, cada vez mais, tornando-se em uma alternativa financeira interessante (GONÇALVES et al., 2014).

Dentre essas espécies que vêm ganhado espaço no cenário florestal brasileiro, está a canafístula (Peltophorum dubium (Spreng.) Taub.), uma planta decídua, heliófita, pioneira pertencente à família Fabaceae, subfamília das Caesalpinioideae, encontrada nos estados da Bahia, Minas Gerais, Mato Grosso do Sul e Paraná, principalmente na floresta latifoliada semidecídua. A madeira da canafístula é moderadamente pesada (densidade de $0,69 \mathrm{~g} / \mathrm{cm}^{3}$ ) sendo utilizada na construção civil, marcenaria, tanoaria, carrocerias, dormente, serviço de torno. Além dessas utilizações, ela é muito utilizada para arborização de praças e rodovias como planta ornamental. Devido à sua rusticidade e ao seu rápido crescimento, é também muito utilizada para composição de reflorestamentos mistos e recomposição de áreas degradadas (LORENZI, 2008).

A exploração das árvores de potencial madeireiro dá-se de forma extrativista e juntamente com a degradação ambiental vem reduzindo o número de indivíduos, uma vez que essas práticas são superiores aos esforços para a busca e manutenção da biodiversidade, levando assim a diminuição das populações, aumentando o risco de perda de material genético insubstituível (VIEIRA et al., 2011). Muitas espécies são pouco conhecidas, apesar de seu grande potencial (SILVA et al., 2009), necessitando de estudos básicos como a análise

FLOREST A, Curitiba, PR, v. 46, n. 4, p. 491 - 498, out. / dez. 2016.

Dutra, T. R. et al.

ISSN eletrônico 1982-4688

DOI: $10.5380 /$ rf.v46i3.44570 
de sustentabilidade de sua exploração e principalmente técnicas que aumentem a viabilidade da produção de mudas para fomentar a implantação de empreendimentos florestais.

O sucesso inicial de qualquer projeto florestal, seja ele para fins conservacionistas ou comerciais, está diretamente relacionado com a qualidade das mudas produzidas, onde uma das formas de se obter plantas mais resistentes, aumentando a chance de sobrevivência no período pós-viveiro, é a utilização de adubações corretas, pois assim proporcionamos seu máximo desenvolvimento, deixando-a preparada para o plantio em campo.

No método tradicional de produção de mudas de arbóreas nativas, a fertilização é realizada por meio do uso de fontes prontamente disponíveis que favorecem uma rápida absorção de nutrientes, entretanto um ponto negativo dessa prática é a alta susceptibilidade à lixiviação devido a grande frequência de irrigação em um viveiro florestal.

Uma das maneiras de aumentar a eficiência das adubações poderia ser o parcelamento da mesma. Porém esse método quando empregado em grandes viveiros acarretaria em maior custo de produção por muda, devido a sucessivos manejos (WILSEN NETO; BOTREL, 2009).

Visando minimizar os problemas citados, os fertilizantes de liberação lenta (FLL) apresentam-se como interessantes alternativas. Esses adubos possuem em sua formulação compostos solúveis (NPK e alguns micronutrientes) envolvidos por uma membrana semipermeável que, por efeito da temperatura, se dilata e se contrai, controlando a liberação gradual e osmótica de nutrientes ao substrato (ROSSA et al., 2013).

Os FLL vêm sendo testados em viveiros e no plantio definitivo para diminuir as perdas de nutrientes por lixiviação e reduzir a mortalidade por choque dos pós plantios (LANG et al., 2011). Apesar de seu custo de aquisição ser elevado, têm sido economicamente viáveis para uso em viveiros florestais, pois, o custo unitário por muda se torna atrativo devido à possibilidade de diminuição de gastos com investimentos em sistemas de fertirrigação e custos com mão-de-obra, caso a adubação seja feita manualmente com regadores (MORAES NETO et al., 2003).

Diante do exposto, o presente trabalho objetivou avaliar o crescimento e a qualidade de mudas de canafístula (Peltophorum dubium (Spreng.) Taub.), em resposta à aplicação de diferentes doses e formulações do fertilizante de liberação lenta Osmocote ${ }^{\circledR}$.

\section{MATERIAL E MÉTODOS}

Foi adotado o delineamento experimental em blocos casualizados, com três repetições, no esquema fatorial 2 x 5, sendo estudado o efeito de duas formulações de Osmocote ${ }^{\circledR}$ (Osmocote ${ }^{\circledR}$ Plus 15-09-12 com tempo de liberação de 5 a 6 meses; e o Osmocote ${ }^{\circledR}$ 19-06-10 MiniPrill Controlled Release com liberação de 3 a 4 meses) e cinco dosagens dos mesmos $\left(0 ; 2,5 ; 5,0 ; 7,5\right.$ e 10,0 $\left.\mathrm{g} \mathrm{dm}^{-3}\right)$. Cada unidade experimental foi constituída por 12 mudas.

O substrato utilizado para produção das mudas foi o Bioplant ${ }^{\circledR}$, cuja caracterização química foi realizada conforme descrito por Empresa Brasileira de Pesquisa Agropecuária (EMBRAPA) (1997). A caracterização física compreendeu a determinação da porosidade total, macroporosidade, microporosidade, densidade aparente e capacidade máxima de retenção de água dos substratos, conforme metodologia proposta por Carvalho e Silva (1992), citado por Dutra et al. (2015) (Tabela 1).

Tabela 1. Características químicas e físicas do substrato utilizado na produção de mudas de canafístula.

Table 1. Chemical and physical characteristics of the substrate used in the production of seedlings canafistula.

\begin{tabular}{llr}
\hline Características & Unidade & \\
\hline pH em água & - & 5,2 \\
Matéria Orgânica & $\mathrm{dag} \mathrm{kg}^{-1}$ & 20,3 \\
Fósforo & $\mathrm{mg} \mathrm{kg}^{-1}$ & 776,57 \\
Potássio & $\mathrm{mg} \mathrm{kg}^{-1}$ & 1,402 \\
Cálcio & $\mathrm{cmol}_{\mathrm{c}} \mathrm{dm}^{-3}$ & 12,20 \\
Magnésio & $\mathrm{cmol}_{\mathrm{c}} \mathrm{dm}^{-3}$ & 4,79 \\
Alumínio & $\mathrm{cmol}_{\mathrm{c}} \mathrm{dm}^{-3}$ & 0,17 \\
Acidez potencial (H+Al) & $\mathrm{cmol}_{\mathrm{c}} \mathrm{dm}^{-3}$ & 8,1 \\
Capacidade efetiva de troca de cátions (t) & $\mathrm{cmol}_{\mathrm{c}} \mathrm{dm}^{-3}$ & 20,69 \\
Capacidade de troca de cátions a pH 7 (T) & $\mathrm{cmol}_{\mathrm{c}} \mathrm{dm}^{-3}$ & 28,69 \\
Soma de bases (SB) & $\mathrm{cmol}_{\mathrm{c}} \mathrm{dm}^{-3}$ & 20,51 \\
Saturação por alumínio (m) & $\%$ & 1,0 \\
Saturação por bases (V) & $\%$ & 73 \\
Porosidade Total & $\%$ & 62,50 \\
Macroporosidade & $\%$ & 19,61 \\
Microporosidade & $\%$ & 43,04 \\
Densidade aparente & $\%$ & 0,1 \\
Capacidade Máxima de Retenção de Água & $\mathrm{kg} \mathrm{dm}^{-3}$ & 23,79 \\
\hline
\end{tabular}


As diferentes formulações e suas respectivas dosagens foram aplicadas ao substrato e homogeneizadas de forma manual, onde posteriormente foram destinadas para o preenchimento de tubetes com capacidade volumétrica de $55 \mathrm{~cm}^{3}$, sendo esses identificados e dispostos em bandejas de polipropileno tipo caixa (620 x 420 x $165 \mathrm{~mm}$ ) com 187 células.

As sementes de canafístula foram coletadas de 10 árvores matrizes localizadas no município de SalinasMG. Após a coleta, as mesmas foram submetidas à superação da dormência por meio da imersão em água quente a $95{ }^{\circ} \mathrm{C}$, deixando-as em repouso fora do aquecimento por 24 horas à temperatura ambiente de $25^{\circ} \mathrm{C}$ (DUTRA et al., 2013).

As sementes foram desinfestadas em solução de hipoclorito de sódio (2\%) por 3 minutos e semeadas em número de três sementes por tubetes, já previamente preenchidos com o Bioplant ${ }^{\circledR}$ em seus diferentes arranjos experimentais avaliados. Os tubetes foram mantidos sob irrigação por microaspersores bailarina com vazão de $85 \mathrm{~L} \mathrm{~h}^{-1}$ em viveiro coberto com sombrite de $50 \%$. A temperatura e umidade relativa do ar média durante o período experimental foi, respectivamente, de $30,1^{\circ} \mathrm{C}$ e $51,3 \%$.

Aos 15 dias após a semeadura (DAS) foi realizado um primeiro raleio, deixando-se duas plântulas por tubete. Aos 30 DAS foi realizado o segundo raleio, deixando-se apenas uma plântula por recipiente.

A partir do $30^{\circ} \mathrm{DAS}$, as mudas receberam fertirrigação semanal com $6 \mathrm{~mL}$ planta $^{-1}$ de solução aquosa contendo $4 \mathrm{~g} \mathrm{~L}^{-1}$ de sulfato de amônio, $10 \mathrm{~g} \mathrm{~L}^{-1}$ de superfosfato simples, $4 \mathrm{~g} \mathrm{~L}^{-1}$ de cloreto de potássio e $1 \mathrm{~g} \mathrm{~L}^{-1}$ de FTE BR12 (9 \% Zn, $3 \%$ Fe, $2 \% \mathrm{Mn}, 0,1 \% \mathrm{Mo}, 1,8 \% \mathrm{~B}, 0,8 \% \mathrm{Cu})$.

Aos 180 dias após semeadura foram avaliadas as seguintes características: altura $(\mathrm{H} ; \mathrm{cm})$ e diâmetro do coleto $(\mathrm{DC} ; \mathrm{mm})$ das mudas. A mensuração da altura das mudas foi realizada com o auxílio de uma régua milimetrada posicionada ao nível do solo até o meristema apical das mesmas. O diâmetro foi medido por meio do uso de um paquímetro digital da marca Western.

Ao final das avaliações anteriores, as plantas foram colhidas e separadas em parte aérea e sistema radicular, lavadas em água corrente e secas em estufa com circulação forçada de ar, a aproximadamente $65^{\circ} \mathrm{C}$, até peso constante. Foram obtidos massa seca da parte aérea (MSPA; g planta ${ }^{-1}$ ), massa seca da raiz (MSR; g planta $\left.^{-1}\right)$ e massa seca total $\left(\right.$ MST $=$ MSPA + MSR; g planta $\left.{ }^{-1}\right)$.

Esses parâmetros foram transformados em índices de qualidade de mudas conforme sugerido por Gomes et al. (2002): H/DC, H/MSPA, MSPA/MSR e no Índice de Qualidade de Dickson - IQD (DICKSON et al., 1960), calculado por:

$$
I Q D=\operatorname{MST}(\mathrm{g}) /[H(\mathrm{~cm}) / D C(\mathrm{~mm})+\operatorname{MSPA}(\mathrm{g}) / \operatorname{MSR}(\mathrm{g})]
$$

Os dados obtidos foram submetidos à análise de variância e quando o efeito do tipo de formulação do adubo de liberação lenta avaliado foi significativo, as médias foram comparadas pelo teste de $\mathrm{F}(\mathrm{P}<0,05)$. Os efeitos das doses Osmocote ${ }^{\circledR}$ foram analisados por meio de regressões, sendo apresentadas somente as equações cujos coeficientes de maior grau foram significativos $(\mathrm{p}<0,05)$.

\section{RESULTADOS E DISCUSSÃO}

Para as variáveis diâmetro do coleto (DC) e massa seca aérea (MSPA) ocorreu efeito significativo da interação entre as diferentes doses e formulações do fertilizante de liberação lenta (FLL) Osmocote ${ }^{\circledR}$ (Figura 1).

A análise do comportamento das variáveis DC e MSPA demonstra uma resposta distinta entre as duas formulações do FLL e as diferentes concentrações avaliadas. Para o fertilizante 19-06-10, de menor tempo de liberação, essas variáveis apresentaram uma resposta quadrática positiva (Figuras 1a e 1b). O fertilizante 15-0912, com tempo de liberação de 5 à 6 meses apresentou uma resposta linear crescente (Figuras 1a e 1b) indicando que valores maiores de diâmetro e produção de massa seca aérea das mudas de canafístula poderiam ser alcançadas em doses superiores a $10 \mathrm{~g} \mathrm{dm}^{-3}$.

Devido a resposta quadrático do FLL de 19-06-10 foi possível a determinação da dose de máxima eficiência técnica para o crescimento em diâmetro do coleto e produção de MSPA, sendo de 5,2 e 7,0 $\mathrm{g} \mathrm{dm}^{-3}$, respectivamente. Percebeu-se que na produção de massa aérea o fertilizante 19-06-10 obteve médias superiores ao FLL 15-09-12, entretanto, devido a sua resposta quadrática, houve queda nos valores médios a partir da concentração de 7,0 $\mathrm{g} \mathrm{dm}^{-3}$, atingindo uma menor MSPA no tratamento com a maior dose do FLL $\left(10 \mathrm{~g} \mathrm{dm}^{-3}\right)$ (Figura 1). Esse comportamento pode ser atribuído à mais rápida disponibilidade total dos nutrientes, proporcionando um desenvolvimento precoce das mudas à medida que se aumentavam as doses, entretanto, devido ao fornecimento nutricional ter ocorrido em um menor período (3 à 4 meses) quando comparado ao FLL

FLOREST A, Curitiba, PR, v. 46, n. 4, p. 491 - 498, out. / dez. 2016.

Dutra, T. R. et al.

ISSN eletrônico 1982-4688

DOI: $10.5380 /$ rf.v46i3.44570 
15-09-12 (5 à 6 meses), houve prejuízo posterior para as mesmas até os 180 dias, já que precisavam manter a biomassa produzida com a ausência do fertilizante.

$$
\text { - FLL 19-06-10 (3 à } 4 \text { meses) } \quad \triangle \quad \text { FLL 15-09-12 (5 à } 6 \text { meses) }
$$

a)
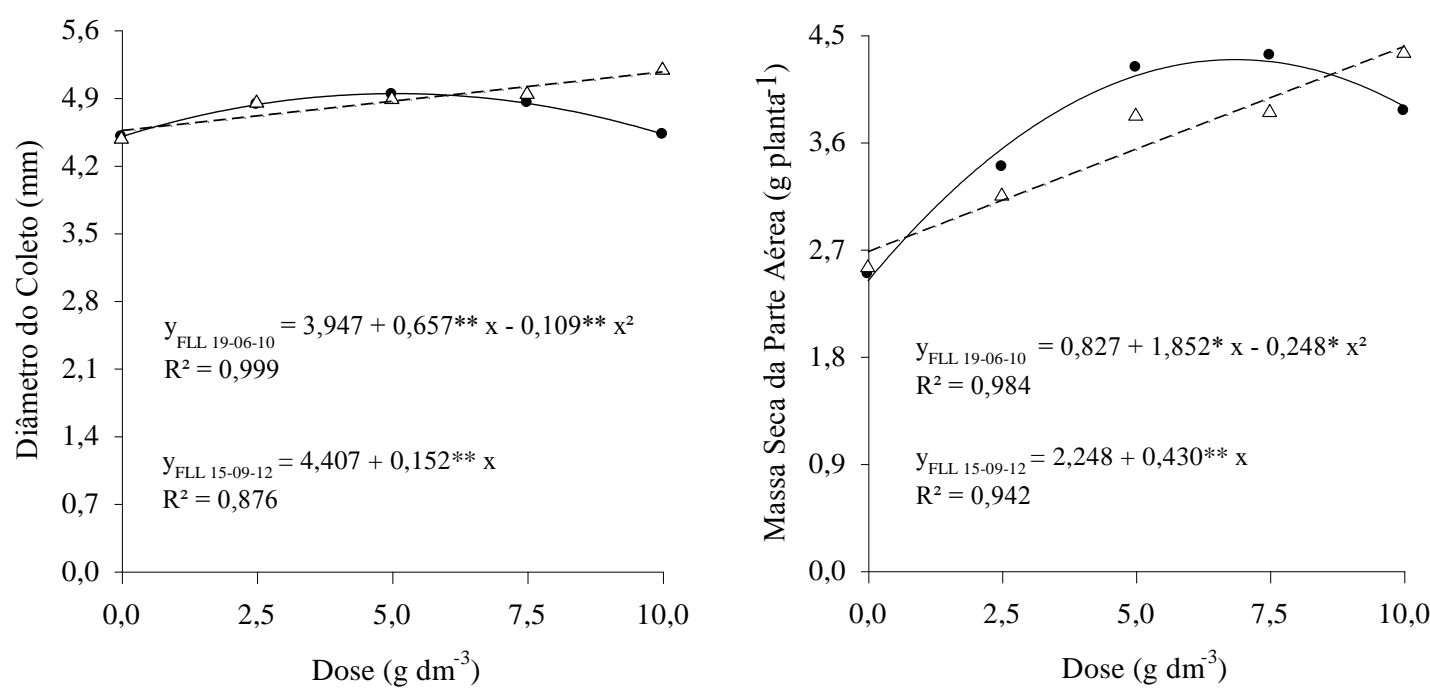

Figura 1. Diâmetro do coleto (a) e produção de massa seca da parte aérea (b) de mudas de canafístula (Peltophorum dubium) em resposta a diferentes doses e duas formulações do fertilizante de liberação lenta.

Figure 1. Collect diameter (a) and dry matter production (b) of the aerial part of canafistula seedlings (Peltophorum dubium) in response to different doses and two formulations of slow release fertilizer.

Comparando os efeitos de diferentes doses de fertilizante de deliberação lenta no crescimento de mudas de Gallesia integrifolia (Spreng.) Harms. (pau d'alho), Rossa et al. (2014) observaram uma elevação das médias de DC e MSPA até as doses de 6,0 e $8,0 \mathrm{~g} \mathrm{dm}^{-3}$, e posteriormente uma queda nos valores das mesmas na concentração de $10 \mathrm{~g} \mathrm{dm}^{-3}$. Esse comportamento também foi observado por Rossa et al. (2011) e Mendonça et al. (2008) avaliando o crescimento de Araucaria angustifolia (Bert.) O. Ktze. e tamarindeiro (Tamarindus indica L), respectivamente, sob diferentes concentrações de FLL em seu substrato de crescimento.

Notou-se que o período de 180 dias, referente ao tempo de condução do trabalho, não foi um fator limitador ao bom crescimento das mudas de canafístula produzidas com o FLL 19-06-10 uma vez que os valores médios obtidos de DC e MSPA das mesmas foram bem próximos e até mesmo maiores aos observados para o fertilizante 15-09-12 (Figura 1).

O crescimento em altura, a produção de massa seca de raiz e total, além das relações altura diâmetro do coleto (H/DC), altura massa seca da parte aérea (H/MSPA) e massa seca aérea e massa seca de raiz (MSPA/MSR) foram influenciadas significativamente de forma isolada pelas doses do FLL avaliadas (Figura 2).

Notou-se que as variáveis altura (Figura 2a), MSR (Figura 2b), MST (Figura 2c) e H/DC (Figura 2d) apresentaram resposta quadrática e responderam positivamente à elevação da concentração do FLL no substrato até as doses máximas de 5,$4 ; 7,7 ; 8,2$ e $4,5 \mathrm{~g} \mathrm{dm}^{-3}$.

Zamunér Filho et al. (2012) também observaram uma resposta quadrática positiva ao aumento das doses de Osmocote ${ }^{\circledR}$ para as variáveis altura, massa seca da parte aérea, raiz e total no desenvolvimento de porta enxertos de seringueira (Hevea brasiliensis (Willd. ex Adr. de Juss.) Müell. Arg.). Os autores concluíram que a dose de $6,0 \mathrm{~g} \mathrm{dm}^{-3}$ foi capaz de promover um desenvolvimento mais completo das plantas, bem como uma melhor nutrição das mesmas. Comportamentos semelhantes para as mesmas variáveis descritas anteriormente foram observados em mudas de angico branco (Anadenanthera colubrina (Veloso) Brenan) (BRONDANI et al., 2008) e Eucalyptus grandis W. Hill ex Maiden (ROSSA et al., 2015) com diferentes doses de máxima eficiência técnica variando de 1,6 a $2,7 \mathrm{~g} \mathrm{dm}^{-3}$ e 9,1 a $11,8 \mathrm{~g} \mathrm{dm}^{-3}$, respectivamente. 
a)

b)
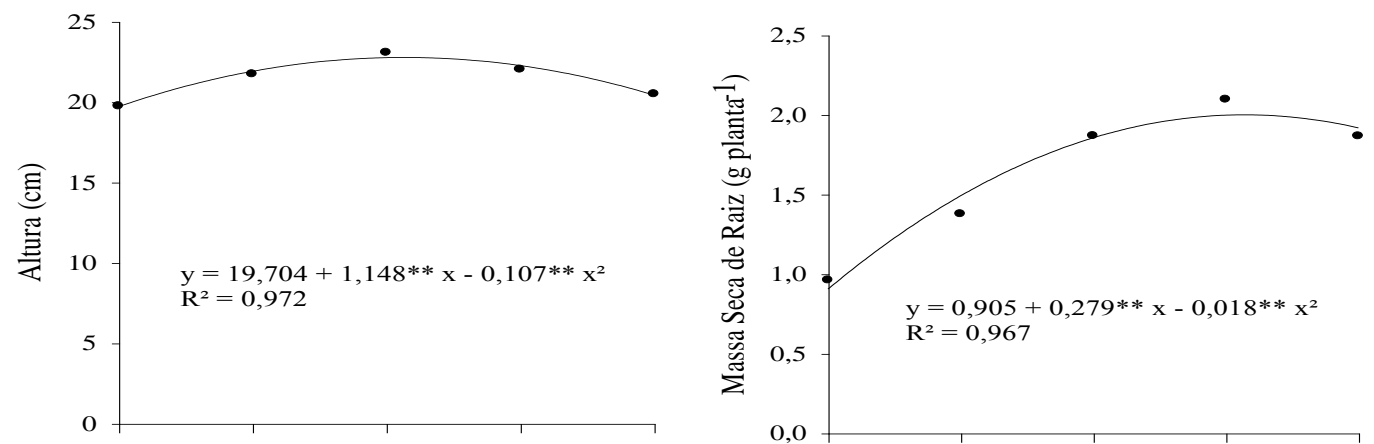

c)
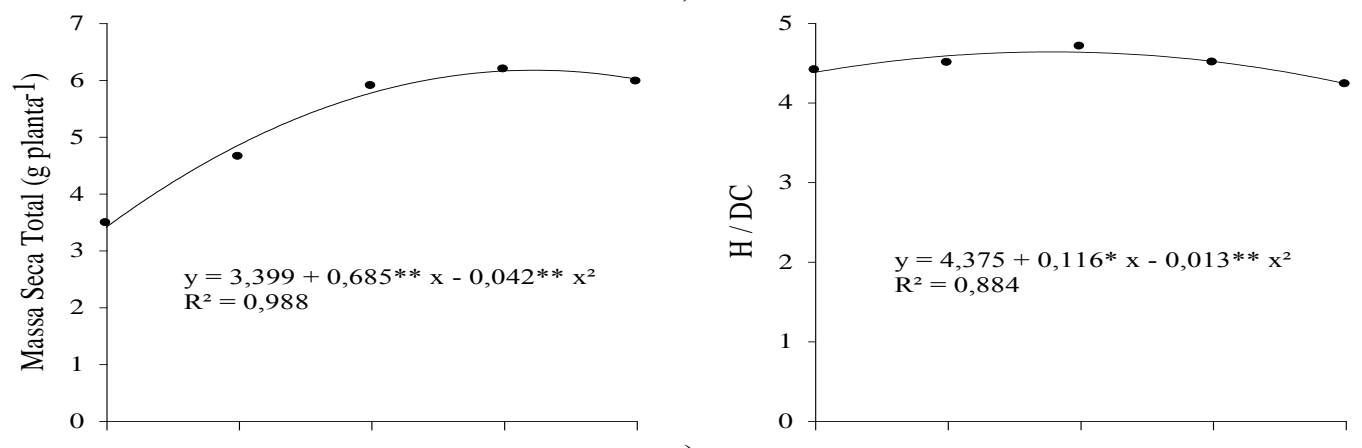

e)
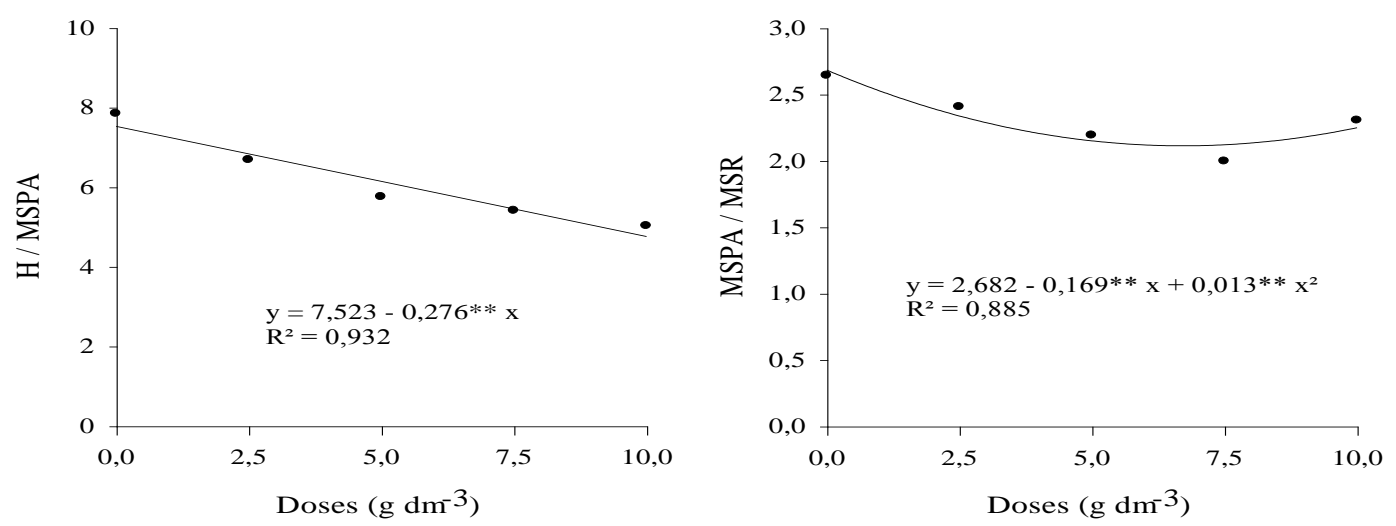

Figura 2. Altura (a), produção de massa seca de raiz (b) e total (c), relação entre altura e diâmetro do coleto (H/DC) (d), relação entre altura e massa seca aérea (H/MSPA) (e) e relação entre massa seca aérea e massa seca de raiz (MSPA/MSR) (f) em mudas de canafístula (Peltophorum dubium) em resposta a diferentes doses do fertilizante de liberação lenta.

Figure 2. Height (a), dry matter production of roots (b) and total (c) relationship between height and stem diameter (H/DC) (d), relationship between shoot and dry mass of shoots (H/MSPA) (e) and ratio of dry pasta shoot and root dry weight (MSPA/MSR) (f) of canafistula seedlings (Peltophorum dubium) in response to different doses of slow release fertilizer.

Assim, a diferença de valores entre as doses recomendadas para cada espécie florestal do FLL reforça a ideia da necessidade de estudos particulares, buscando um melhor desenvolvimento das plantas e a otimização no uso da técnica, sendo difícil a realização de uma recomendação padrão.

Quando comparadas ao tratamento sem a presença do FLL, as doses ótimas estimadas para o maior crescimento em altura (Figura 2a), MSR (Figura 2b) e MST (Figura 2c) foram capazes de proporcionar ganhos médios percentuais de 15,42; 106,79 e 78,0\%, respectivamente, demonstrando assim a grande viabilidade de uso dessa técnica de adubação na produção de mudas da espécie em estudo.

Avaliando a diferença entre a adubação com Osmocote ${ }^{\circledR}$ em duas concentrações $\left(1,75\right.$ e $\left.3,5 \mathrm{~g} \mathrm{dm}^{-3}\right)$ e a adubação convencional com NPK $\left(1,0 \mathrm{~g} \mathrm{dm}^{-3}\right)$ na produção de mudas de canafístula, Brachtvogel e Malavasi 
(2010) observaram que os valores médios de MST e MSPA das mesmas, quando crescidas em sacos plásticos, foram quase duas vezes maiores para o uso do FLL.

A relação entre altura e massa seca aérea (H/MSPA) é sinônimo de rusticidade, onde segundo Gomes et al. (2002) quanto menor for essa relação mais lignificada estará a planta e maior a sua capacidade de sobrevivência em campo. Devido à resposta linear decrescente apresentada pela canafístula para essa variável, seu potencial de rusticidade aumenta à medida que se eleva a concentração do FLL no substrato de crescimento das mudas (Figura 2e).

A relação entre as massas secas aérea e do sistema radicular das mudas (MSPA/MSR) é considerada como um parâmetro eficiente e seguro para expressar seu padrão de qualidade (GOMES et al., 2002). Segundo Brissette (1984) ficou estabelecido que um valor igual a 2,0 seria o melhor índice dessa relação de uma mesma planta. Pode-se observar que mesmo com uma resposta quadrática negativa à elevação das doses do FLL, os valores médios obtidos estão próximos ou acima de 2,0 (Figura 2f), levando à dedução de que, por esse índice e para as concentrações testadas, as mudas de canafístula atingiram um bom padrão de qualidade.

Houve efeito significativo, de forma isolada, das duas formulações de FLL testadas para as variáveis altura, produção de MSR e MST, além das relações H/MSPA e MSPA/MSR (Figura 3).
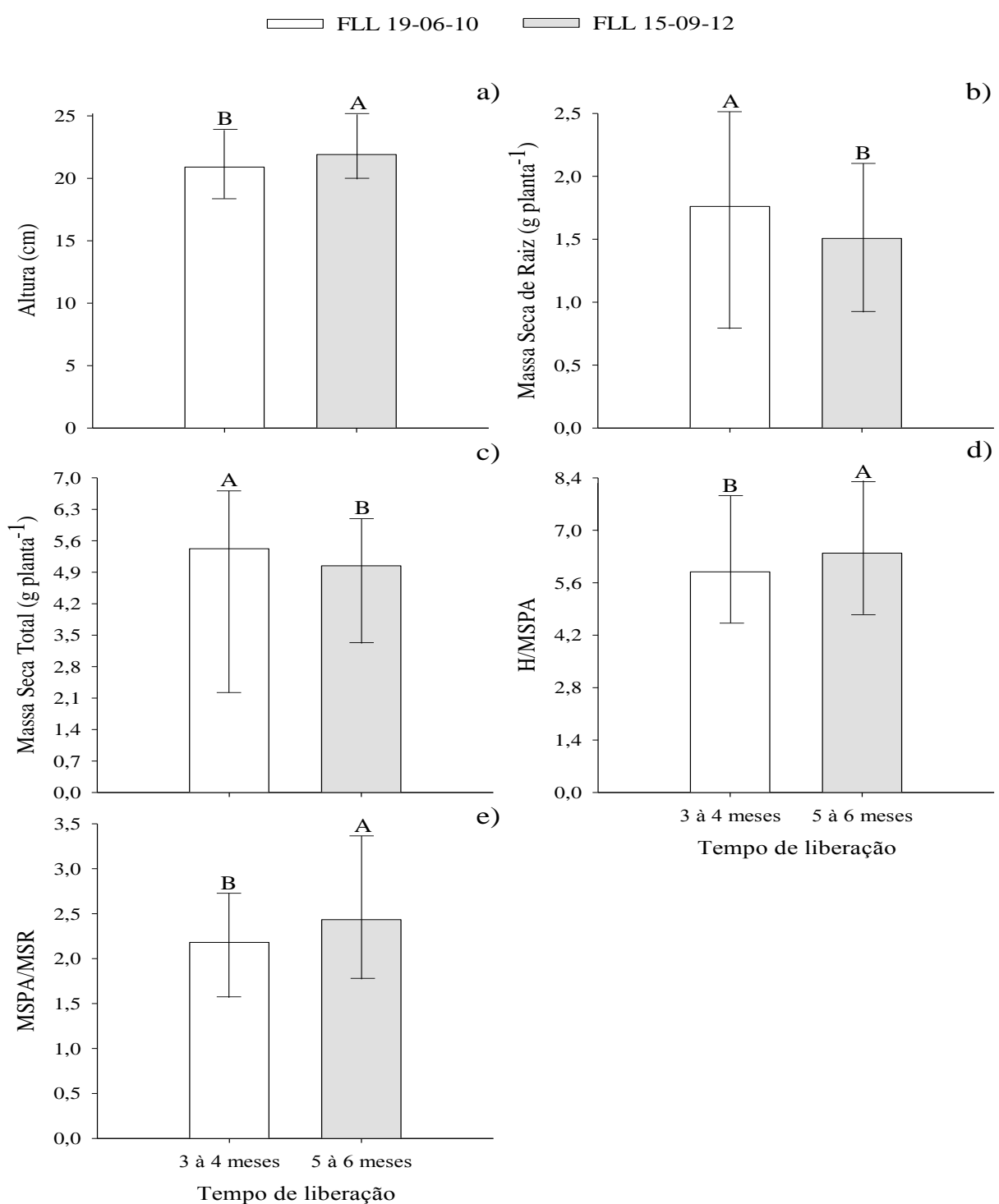

Figura 3. Altura (a), massa seca de raiz (b) e total (c), relação entre altura da parte aérea e massa seca da parte aérea (H/MSPA) (d) e relação entre massa seca da parte aérea e massa seca de raiz (MSPA/MSR) (e) de mudas de canafístula (Peltophorum dubium) em resposta a duas formulações do fertilizante de liberação. Letras distintas se diferem pelo teste F. 
Figure 3. Height (a), dry matter of root (b) and total (c) relationship between shoot height and dry mass of shoots (H/MSPA) (d) and relationship between dry weight of shoot and root dry weight (MSPA/MSR) (e) of canafistula seedlings (Peltophorum dubium) in response to two formulations of slow release fertilizer. Different letters differ by $F$ test.

Observou-se que a formulação 19-06-10, com tempo de liberação de 3 à 4 meses, apresentou médias maiores de MSR (Figura 3b) e MST (Figura 3c), além de um menor valor para a relação H/MSPA (Figura 3d), o que se reflete em mudas mais bem estruturadas e com maior capacidade de sobrevivência em campo (GOMES et al. 2002). Diante dessas respostas, pode-se inferir que a formulação 19-06-10 foi capaz de proporcionar a produção de mudas de canafístula com boa qualidade, apesar do tratamento com FLL 15-09-12 ter apresentado os maiores valores médios de altura $(21,9 \mathrm{~cm}$ ) (Figura 3a) e MSPA/MSR $(2,434)$ (Figura 3e). O FLL 19-06-10 resultou em valor de altura bem próxima $(20,9 \mathrm{~cm})$ ao obtido com adição de 15-09-12, além de uma relação entre massa seca aérea e massa seca de raiz $(2,181)$ superior a 2,0 (BRISSETTE, 1984).

Os resultados proporcionados pelo fertilizante 19-06-10 para essas variáveis vão de encontro ao observado para a produção de massa seca aérea e diâmetro do coleto das mudas de canafístula do presente trabalho (Figura 1). Para as duas variáveis o FLL 19-06-10 também foi capaz de promover médias iguais e até mesmo superiores ao FLL 15-09-12 em diferentes doses testadas.

Não houve efeito significativo do tipo de fertilizante para a variável IQD, ou seja, as mudas de canafístula obtiveram o mesmo padrão de qualidade independentemente da formulação e tempo de liberação, reforçando dessa forma, a opção pelo FLL 19-06-10.

\section{CONCLUSÕES}

- As mudas de canafístula responderam ao uso do fertilizante de liberação lenta Osmocote ${ }^{\circledR}$, apresentando melhores crescimento e padrão de qualidade sob doses entre 5,4 a $8,2 \mathrm{~g} \mathrm{dm}^{-3}$;

- A formulação de Osmocote ${ }^{\circledR} 19-06-10$ com tempo de liberação de 3 a 4 meses foi capaz de proporcionar a produção de mudas de Peltophorum dubium com melhor crescimento.

\section{AGRADECIMENTOS}

À CAPES/Prodoutoral pela concessão de bolsas ao primeiro e segundo autores.

Ao Instituto Federal do Norte de Minas Gerais - Campus Salinas pela concessão de bolsa de iniciação científica ao terceiro autor.

\section{REFERÊNCIAS}

BRACHTVOGEL, E. L.; MALAVASI, U. C. Volume do recipiente, adubação e sua forma de mistura ao substrato no crescimento inicial de Peltophorum dubium (Sprengel) Taubert em viveiro. Revista Árvore, Viçosa, v. 34, n. 2, p. 223-232, 2010.

BRONDANI, G. E.; SIlVA, A. J. C.; REGO, S. S.; GRISI, F. A.; NOGUEIRA, A. C.; WENDLING, I.; ARAUJO, M. A. Fertilização de liberação controlada no crescimento inicial de angico branco. Scientia Agraria, Curitiba, v. 9, n. 2, p. 167-176, 2008.

BRISSETTE, J. C. Summary of discussions about seedling quality. In: Southern Nursery Conferences, 1984, Alexandria. Proceedings New Orleans: USDA. Forest Service. Southern Forest Experiment Station, 1984. p. 127-128.

DICKSON, A.; LEAF, A, L.; HOSNER, J. F. Qualitty appraisal of white spruce and white pine seedling stock in nurseries. Forestry Chronicle, v. 36, p. 10-13, 1960.

DUTRA, T. R.; GRAZZIOTTI, P. H.; SANTANA, R. C.; MASSAD, M. D. Qualidade de mudas de copaíba produzidas em diferentes substratos e níveis de sombreamento. Floresta, Curitiba, v. 45, n. 3, p. 635-644, 2015.

DUTRA, T. R.; MASSAD, M. D.; SARMENTO, M. F. Q.; OLIVEIRA, J. C. Substratos alternativos e métodos de quebra de dormência para produção de mudas de canafístula. Revista Ceres, Viçosa, v. 6, n. 1, p. 72-78, 2013.

EMPRESA BRASILEIRA DE PESQUISA AGROPECUÁRIA (EMBRAPA). Manual de métodos de análise de solo. Rio de Janeiro: Centro Nacional de Pesquisa de Solo, 1997. 212 p. 
GOMES, J. M.; COUTO, L.; LEITE, H. G.; XAVIER, A.; GARCIA, S. L. R. Parâmetros morfológicos na avaliação da qualidade de mudas de Eucalyptus grandis. Revista Árvore, Viçosa, v. 26, n. 6, p. 655-664, 2002.

GONÇALVES, E. O.; PAIVA, H. N.; NEVES, J. C. L.; KLIPPEL, V. H.; CALDEIRA, M. V. W. Crescimento de Dalbergia nigra (Vell.) Allemão ex Benth sob diferentes doses de cálcio, magnésio e enxofre. Revista Árvore, Viçosa, v. 38, p. 251-260, 2014.

LANG, A.; MALAVASI, U. C.; DECKER, V.; PÉREZ, P. V.; ALEIXO, M. A.; MALAVASI, M. M. Aplicação de fertilizantes de liberação lenta no estabelecimento de mudas de ipê-roxo e angico-branco em área de domínio ciliar. Revista Floresta, Curitiba, v. 41, n. 2, p. 271-276, 2011.

LORENZI, H. Arvores Brasileiras: Manual de identificação e cultivo de plantas arbóreas nativas do Brasil. Instituto Plantarium, vol. 1, $5^{\circ}$ edição, Nova Odessa, São Paulo, 2008, 352 p.

MENDONÇA, V.; ABREU, N. A. A.; SOUZA, H. A.; TEIXEIRA, G. A.; HAFLE, O. M.; RAMOS, J. D. Diferentes ambientes e osmocote ${ }^{\circledR}$ na produção de mudas de tamarindeiro (Tamarindus indica). Ciência e agrotecnoloiga, Lavras, v. 32, n. 2, p. 391-397, 2008.

MORAES NETO, S. P.; GONÇALVES, J. L. M.; RODRIGUES, C. J.; GERES, W. L. A.; DUCATTI, F.; AGUIRRE JÚNIO, J. H. Produção de mudas de espécies arbóreas nativas com combinações de adubos de liberação controlada e prontamente solúveis. Revista Árvore, Viçosa, v. 27, n. 6, p. 779-789, 2003.

ROSSA, U. B.; ANGELO, A. C.; BOGNOLA, I. A.; WESTPHALEN, D. J.; MILANI, J. E. F. Fertilizante de liberação lenta no desenvolvimento de mudas de Eucalyptus grandis. Floresta, Curitiba, v. 45, n. 1, p. 85-96, 2015.

ROSSA, U. B.; ANGElO, A. C.; NOGUEIRA, A. C.; REISSMANN, C. B.; GROSSI, F.; RAMOS, M. R. Fertilizante de liberação lenta no crescimento de mudas de Araucaria angustifolia e Ocotea odorifera. Floresta, Curitiba, v. 41, n. 3, p. 491-500, 2011.

ROSSA, U. B.; ANGELO, A. C.; NOGUEIRA, A. C.; WESTPHALEN, D. J.; BASSACO, A. V. M.; MILANI, J. E. F.; BIANCHIN, J. E. Fertilizante de liberação lenta no desenvolvimento de mudas de Schinus terebinthifolius e Sebastiania commersoniana. Floresta, Curitiba, v. 43, n. 1, p. 93-104, 2013.

ROSSA, U. B.; ANGELO, A. C.; WESTPHALEN, D. J.; UTIMA, A. Y.; MILANI, J. E. F.; MONZANI, R. M. Fertilizante de liberação lenta na produção de mudas de Gallesia integrifolia (Spreng.) Harms. Revista Agrocientífica, Joaçaba, v. 1, n. 1, p. 23-32, 2014.

SILVA, E. A.; MARUYAMA, W. I.; OLIVEIRA, A. C.; BARDIVIESSO, D. M. Efeito de diferentes substratos na produção de mudas de mangabeira (Hancornia speciosa). Revista Brasileira de Fruticultura, Jaboticabal, v. 31, n. 3, p. 925-929, 2009.

VIEIRA, C. R. V.; WEBER, O. L. S.; SCARAMUZZA, J. F.; COSTA, A. C.; SOUZA, T. R. Descrição de sintomas visuais em função das deficências de macronutrientes em mudas de cerejeira (Amburana acreana). Revista Floresta, Curitiba, v. 41, n. 4, p. 789-796, 2011.

WILSEN NETO, A.; BOTREL, M. C. G. Doses de fertilizantes de liberação lenta na produção de mudas de pinus. Agrarian, Dourados, v. 2, n. 3, p. 65-72, 2009.

ZAMUNÉR FILHO, A. N.; VENTURIN, N.; PEREIRA, A. V.; PEREIRA, E. B. C.; MACEDO, R. L. G. Dose of controlled-release fertilizer for production of rubber tree rootstocks. Cerne, Lavras, v. 18, n. 2, p. 239-245, 2012. 